\title{
Comprehensive Evaluation of Drought Stress Tolerance of Twenty Species of Lettuce at the Seed Germination Stage during PEG 6000 Stress
}

\author{
Chao-jie LIU ${ }^{a}$, Yu-lin DUAN ${ }^{b}$, Lin WANG, Ying-yan HAN, Jing-hong \\ HAO and Shuang-xi FAN",
}

College of Plant Science and Technology, Beijing University of Agriculture/Beijing Key Laboratory for Agricultural Application and New Technique/National Demonstration Center for Experimental Plant Production Education, Beijing 102206, China

acliu@bua.edu.cn, b906702874@qq.com, ${ }^{\text {cfsx}}$ 20@163.com

${ }^{*}$ Corresponding author

Keywords: Lettuce, Drought stress, Cluster analysis.

\begin{abstract}
Objective] The goal is to understand the drought tolerance of lettuce and effectively distinguish between cultivars that are drought tolerant and those that are drought sensitive. [Method] This study was performed to evaluate twenty lettuce cultivars for their sensitivity to drought stress induced by polyethylene glycol (PEG) 6000 at a concentration of $200 \mathrm{~g} / \mathrm{L}$ during germination and the seedling growth stage of plant development. The final germination percentage, sprout potential and the relative germination rates and root lengths were measured during experimental conditions. Experimental units were arranged in a factorial completely randomized design with three replications. The data were used for principal component analysis, membership function analysis, and cluster analysis. [Result] The mean comparison showed that the cultivar 'American fast-growing No. 9' exhibited the highest value for most of the parameters recorded. The cultivar that was the most sensitive to drought was 'Victoria glass crispy lettuce'. [Conclusion] The results of the variance analysis clearly indicated that the combination of the germination and seedling growth parameters used in this study can serve to discriminate between tolerant and sensitive cultivars during drought stress in breeding programmers and that this type of laboratory experiment appears to be suitable to screen lettuce cultivars during drought stress.
\end{abstract}

\section{Introduction}

Abiotic stress, especially drought stress, is a worldwide problem, seriously constraining global crop production [Pan, X.Y et al., 2002]. It is one of the major causes of crop loss worldwide and commonly reduces the average yield for many crop plants by more than 50\% [Bayoumi, $\mathrm{T}$ et al., 2008]. It adversely affects plant growth, development and productivity [Baier M, 2005]. China has taken a series of actions to conserve water resources including engineering, economic, administrative and technical measures. The primary method should involve water conservation measures directly related to agriculture. Water-saving irrigation and the cultivation of drought resistant varieties are the primary ways to solve the problem of drought resistance to conserve water. The high yield of a plant in sufficiently irrigated conditions does not necessarily correlate with high yield during drought stress [Vahidi, J. 2009]. Depending on the stage of growth at which a plant experiences drought stress, it can react differently to the stress [Galies, J. and Ho, T.D., 1983]. The plant may be affected by 
drought at any time during its life cycle. However, plants are particularly sensitive at stages such as germination and seedling growth [Pessarakli, M. 1999].

Lettuce (Lactuca sativa L.) is a widely grown and popularly consumed vegetable worldwide. The largest producer of lettuce in the world is China, which primarily produces a stem lettuce (L. sativa L. var. Augustine) that is not commonly consumed in the US or Western Europe [Mou, 2008]. The US and Western Europe produce approximately $22 \%$ and $13 \%$ of the total lettuce crop worldwide, respectively [Mou, 2008]. In the US, lettuce ranks as the third most frequently consumed vegetable [USDA, 2015]. Consumers increasingly demand foods that go beyond nutritional needs to also promote well-being reduce diseases and increase life spans [Baslam et al., 2011]. In China, lettuce is also popular because of its high nutritional value, in particular vitamin $\mathrm{C}$, vitamin $\mathrm{A}, \mathrm{Ca}, \mathrm{P}$ and $\mathrm{Fe}$. Epidemiological studies indicate that there is a correlation between increased vegetable consumption and reduced risks of chronic diseases such as cancer, cardiovascular disease and age-related functional decline [Hung et al., 2004; Morris et al., 2006; Pavia et al., 2006]. These health beneficial effects are thought to be related to the macronutrients, micronutrients and bioactive compounds present in vegetables [Kris-Etherton et al., 2002; Soetan et al., 2010].

Seed germination and seedling growth characteristics are extremely important factors that determine yield [Rauf, M. et al., 2007]. Dhanda et al., [Dhanda et al., 2004] indicated that the seed vigour index and shoot length are among the most sensitive factors to drought stress, followed by root and coleoptile lengths. The rate of seed germination and the final germination percentage, as well as the amount of water absorbed by the seeds, were reduced considerably as the osmotic stress level rose [Heikal, M.M., et al., 1981]. There are many studies, such as the selection of plant species or seed treatments, that can help to alleviate the negative effects of drought stress on plants [Ashraf, M et al., 1992; Almansouri, M et al., 2001; Okcu, G et al., 2005; Kaya, M.D et al., 2006; Iqbal, M and Ashraf, M., 2007]. The selection of drought tolerance at the early seedling stage is frequently carried out using simulated drought induced by chemicals such as polyethylene glycol (PEG 6000).

\section{Materials and Methods}

\section{Materials}

Variety selection of lettuce in Table 1. 
Table 1. Twenty lettuce varieties and manufacturers

\begin{tabular}{|c|c|c|c|}
\hline $\begin{array}{c}\text { Numb } \\
\text { er }\end{array}$ & Variety & $\begin{array}{l}\text { Variety } \\
\text { sources }\end{array}$ & Manufacturer \\
\hline $\mathrm{S} 1$ & $\begin{array}{l}\text { Italian bolting all year lettuce } \\
\text { (green jade } 8)\end{array}$ & Jiedong, China & $\begin{array}{l}\text { Guangdong Teng licensing gold record seed } \\
\text { industry }\end{array}$ \\
\hline $\mathrm{S} 2$ & $\begin{array}{l}\text { Italian full year resistant to } \\
\text { bolting lettuce (A68) }\end{array}$ & $\begin{array}{l}\text { Xinxiang, } \\
\text { China }\end{array}$ & $\begin{array}{c}\text { Xinxiang City, Henan Province Kodak Seed } \\
\text { Co., Ltd }\end{array}$ \\
\hline $\mathrm{S} 3$ & Lvbao & Beijing, China & $\begin{array}{l}\text { Beijing Green Oriental Agricultural } \\
\text { Technology Research Institute }\end{array}$ \\
\hline $\mathrm{S} 4$ & Lalang & United States & Shenyang Jiahe Seed Co., Ltd \\
\hline S5 & Ailv & Italy & Shenyang Jiahe Seed Co., Ltd \\
\hline S6 & Cool Sina 201 lettuce & United States & Ausagro American \\
\hline S7 & Cool Sina 301 lettuce & United States & Ausagro American \\
\hline S8 & Victoria glass crispy lettuce & Italy & Tianjin Xianyouda Seed Co., Ltd. \\
\hline S9 & Summer Walker (Simpson) & United States & Ausagro American \\
\hline S10 & Brera Simpson & Italy & Tianjin Xianyouda Seed Co., Ltd. \\
\hline S11 & Simpson Elite & Chile & $\begin{array}{c}\text { Beijing Haotianfeng Seedling Technology Co., } \\
\text { Ltd }\end{array}$ \\
\hline $\mathrm{S} 12$ & American fast-growing No. 1 & Beijing, China & $\begin{array}{l}\text { Beijing Jindong Yongfeng Agricultural } \\
\text { Science and Technology Co., Ltd }\end{array}$ \\
\hline S13 & American fast-growing No. 2 & Beijing, China & $\begin{array}{l}\text { Beijing Lianhua Spirit Technology } \\
\text { Development Co., Ltd }\end{array}$ \\
\hline S14 & American fast-growing No. 3 & Chile & Royal Seed of the Netherlands Co., Ltd \\
\hline S15 & American fast-growing No. 4 & Hebei, China & Beijing Mikefeng Co., Ltd \\
\hline S16 & American fast-growing No. 5 & Beijing, China & $\begin{array}{l}\text { Beijing Green Oriental Agricultural } \\
\text { Technology Research Institute }\end{array}$ \\
\hline S17 & American fast-growing No. 6 & Beijing, China & $\begin{array}{l}\text { Beijing Haotian Feng Seedling Technology } \\
\text { Co., Ltd }\end{array}$ \\
\hline S18 & American fast-growing No. 7 & United States & Shenyang Jiahe Seed Co., Ltd \\
\hline S19 & American fast-growing No. 8 & Gansu, China & Gansu Dadi Seed Co., Ltd \\
\hline S20 & American fast-growing & Gansu, China & Gansu Dadi Seed Co., Ltd \\
\hline
\end{tabular}

\section{Methods}

Processing of Experimental Materials. To study the effects of drought stress on germination indexes and seedling growth parameters in lettuce using polyethylene glycol, an experiment was conducted at the Beijing Agricultural College Vegetable Laboratory. The form of the experiment was factorial using a completely randomized design (CRD) with three replicates. In this study, the seeds of twenty lettuce cultivars were used, and all of the seeds were obtained from markets.

Lettuce seeds of 20 cultivars were disinfected with $10 \%$ sodium hypochlorite for 30 seconds and then washed twice with distilled water. Fifty seeds from each cultivar were germinated on two layers of filter paper in 9-cm Petri dishes while being treated with $200 \mathrm{~g} / \mathrm{L}$ PEG 6000. The Petri dishes were covered to prevent the loss of moisture by evaporation during 5 days of laboratory conditions $\left(25^{\circ} \mathrm{C}\right)$, and $1 \mathrm{~mL}$ PEG 6000 solution was added each day. The number of seeds that germinated each day was 
recorded. The standard of germination was that the embryo broke through during the experiment.

Determination of the Test Data. The seeds were considered germinated when they exhibited a radicle extension of $>3 \mathrm{~mm}$. Seeds were germinated daily every 24 hours after soaking to determine the germination parameters. The number of germinated seeds recorded 5 days after planting was defined as the final germination percentage (FGP) according to the ISTA [ISTA., 1993] where FGP=Ng / Nt x 100\%, Ng=Total number of germinated seeds and $\mathrm{Nt}=$ Total number of seeds evaluated. The experiment was terminated by harvesting the seedlings 5 days after the seeds had been soaked. Traits including root and bud lengths were measured to calculate the relative root and bud lengths. The measurement method of the related indexes was carried out using the normal method.

Data Processing and Analysis. The data collected was analysed statistically using SPSS 19.0 and Excel 2007 software to identify significant differences among the lettuce varieties and their treatments.

Calculation of Membership Function Values. The comprehensive membership function method was used to evaluate the drought resistance of lettuce. The specific calculation method is as follows: the membership function formula is $\mathrm{R}(\mathrm{Xi})=(\mathrm{Xi}-\mathrm{Xmin}) /(\mathrm{Xmax}-\mathrm{Xmin})$ and the inverse membership function formula is $\mathrm{R}(\mathrm{Xi})=1-(\mathrm{Xi}-\mathrm{Xmin}) /(\mathrm{Xmax}-\mathrm{Xmin}) . \mathrm{Xi}$ is the measured value of the index, while Xmin and $\mathrm{Xmax}$ are the minimum and maximum values of the corresponding indexes.

\section{Results}

\section{Index of Correlation and PCA on the Germination Stage}

For all five germination parameters, data on the effect of PEG-induced stress on FGP, RGR, RSP, RRL, and RSL are shown in Table 2. In all of the parameters, the FGP, RGR, and RSP were the highest at the control treatment and started to decrease as the drought level increased in parallel with the use of PEG. The results showed that the information contained in these three principal components reflects the relationship between the drought resistance of the lettuce in the drought stress environment, and the evaluation index system can be a more effective evaluation of drought resistance in the lettuce seed germination stage [Yu Sung.2008].

Table 2. The drought stress resistance coefficient of measured indicators

\begin{tabular}{cccccc}
\hline Variety & FGP & RGR & RSP & RRL & RSL \\
\hline S20 & 0.85 & 0.95 & 0.99 & 0.92 & 0.49 \\
S9 & 0.78 & 0.95 & 0.97 & 0.74 & 0.42 \\
S8 & 0.47 & 0.89 & 0.85 & 0.71 & 0.44 \\
\hline
\end{tabular}

Note: FGP: Final germination percentage; RGR: Relative germination rate; RSP: Relative sprout potential; RRL: Relative root length;RSL: Relative shoot length. The same as below.

\section{Analysis of Drought Resistance Membership Function}

The membership function was used to evaluate the drought tolerance of plants [Kaur-Sawhney R, 2003] because it is a comprehensive evaluation method. The results are shown in Table 3, and the differences in drought tolerance were consistent with the previous results of drought resistance screening. Thus, the use of the drought resistance index in this study is feasible. 
Table 3. Membership function value of the indicators and evaluation results of drought resistance

\begin{tabular}{ccccccc}
\hline Variety & FGP & RGR & RSP & RRL & RSL & Mean \\
\hline S20 & 1 & 1 & 1 & 1 & 1 & 1 \\
S9 & 0.82 & 1 & 0.86 & 0.14 & 0 & 0.56 \\
S8 & 0 & 0 & 0 & 0 & 0.29 & 0.06 \\
\hline
\end{tabular}

\section{Comprehensive Assessment of Drought Resistance}

Table 4. Membership function value of the indicators and evaluation results of drought resistance

\begin{tabular}{|c|c|c|c|c|}
\hline Number & FGP & RGR & RSP & Mean \\
\hline $\mathrm{S} 1$ & 0.43 & 0.92 & 0.76 & 0.70 \\
\hline $\mathrm{S} 2$ & 0.37 & 0.90 & 0.64 & 0.64 \\
\hline S3 & 0.44 & 0.83 & 0.73 & 0.66 \\
\hline $\mathrm{S} 4$ & 0.41 & 0.92 & 0.55 & 0.62 \\
\hline S5 & 0.42 & 0.75 & 0.67 & 0.61 \\
\hline S6 & 0.58 & 1.00 & 0.71 & 0.77 \\
\hline S7 & 0.41 & 0.75 & 0.52 & 0.56 \\
\hline S8 & 0.00 & 0.33 & 0.00 & 0.11 \\
\hline S9 & 0.41 & 0.84 & 0.70 & 0.65 \\
\hline S10 & 0.19 & 0.54 & 0.20 & 0.31 \\
\hline S11 & 0.56 & 0.75 & 0.88 & 0.73 \\
\hline S12 & 0.49 & 0.76 & 0.76 & 0.67 \\
\hline S13 & 0.54 & 0.98 & 1.00 & 0.84 \\
\hline S14 & 0.54 & 0.94 & 0.94 & 0.81 \\
\hline S15 & 0.48 & 0.83 & 0.79 & 0.70 \\
\hline S16 & 0.48 & 0.90 & 0.80 & 0.73 \\
\hline S17 & 0.70 & 0.84 & 0.79 & 0.78 \\
\hline S18 & 0.75 & 0.83 & 0.76 & 0.78 \\
\hline S19 & 0.18 & 0.00 & 0.17 & 0.12 \\
\hline S20 & 1.00 & 1.00 & 0.94 & 0.98 \\
\hline
\end{tabular}

The average membership function showed the difference in drought tolerance between twenty kinds of lettuce in Table 4. The results clearly showed that different lettuce cultivars varied in their response to drought stress at the stages of germination and early seedling growth. The confined seedling environment of the laboratory appears to be suitable to screen large populations to improve drought tolerance prior to yield testing. All other germination and seedling growth traits that were studied can be used as selectable characters to discriminate between resistant and sensitive cultivars during drought stress in breeding programmes. 


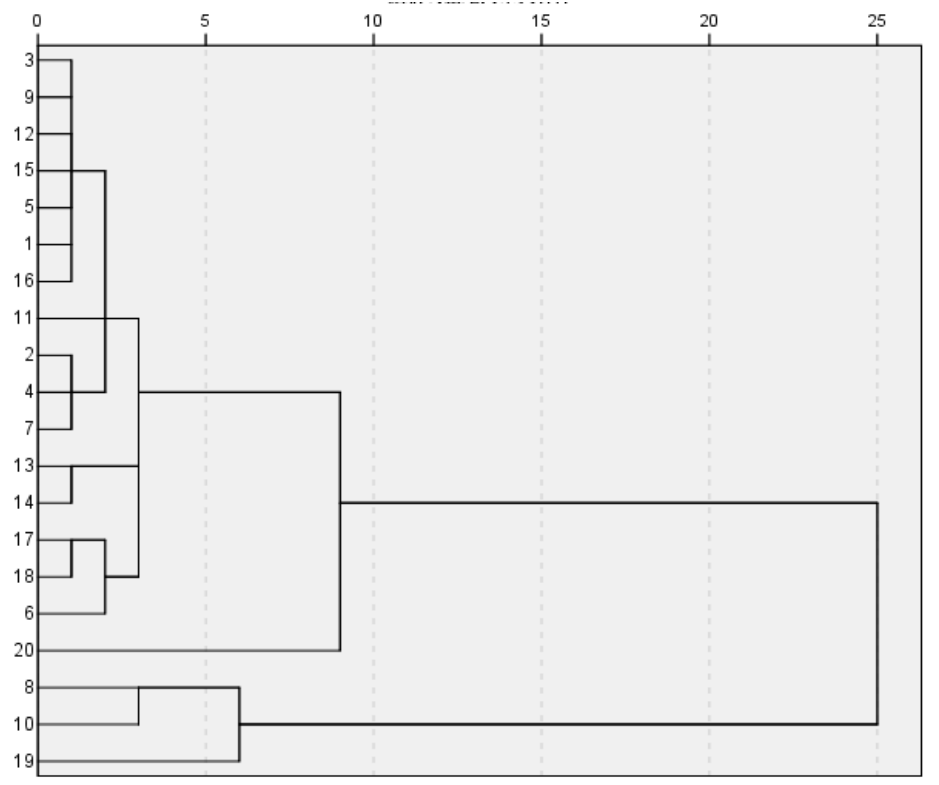

Figure 1. Cluster analysis of relative indexes of 20 cultivars at germination stage in lettuce

To find the cultivar that is the most tolerant of the drought conditions, an analysis of all of the traits examined in this study indicated that the twenty cultivars can be classified into three groups depending on their ability to tolerate the osmotic stress as shown in Fig. 1. The first (the highly resistant group) includes 'American fast-growing number 9'; the second (sensitive group) includes 'Victoria glass crispy lettuce', 'Brera Simpson' and 'American fast-growing number 8', and the third (moderate group) includes the rest of the cultivars.

\section{Discussion}

Since PEG 6000 solutions are non-toxic and less prone to be absorbed by plants, they have been widely used to identify drought resistant cultivars of various crops. Different concentrations of PEG 6000 can be used to examine the drought resistance of different crops and methods. The published literature includes many studies on the drought resistance of plant seedlings using morphological indexes [Muhammad K.2007]. However, there are still few studies on the results of drought resistance characteristics research on plants. In this study, drought stress was simulated using the optimal concentration of PEG 6000 solution $(200 \mathrm{~g} / \mathrm{L})$. The optimal concentration was identified from previous studies, and the FGP, RGR, RSP, RRL, and RSL were analysed by principal component analysis. Finally, we selected the three main drought resistance indicators including FGP, RGR, and RSP, and we used the membership function analysis method to evaluate the 20 types of lettuce. The results were divided into three groups by cluster analysis, and the results showed that the most drought resistant cultivar in this experiment was the lettuce known as 'American fast-growing number 9'. The identification of potentially drought tolerant varieties and the information from this study may be helpful for growers to select cultivars during drought conditions. In addition, this study advances the genetic improvement of lettuce to drought stress.

The drought resistance of vegetables is a complex comprehensive trait. Different varieties have varying mechanisms of drought resistance, and even the same species can have different degrees of difference. In the existing research on the drought resistance 
of vegetables, there are three main methods used including principal component analysis, membership function analysis, and cluster analysis. If the growth period of the vegetables is studied, more accurate classification results could be obtained. In this experiment, the drought resistance of the lettuce was discussed, which provided the basis for considering its drought resistance.

The data from the experiments of the drought resistance of 20 different varieties of lettuce were sorted by their membership function values. The first group of drought resistant varieties which includes the lettuce cultivar 'American fast-growing number 9' has the greatest degree of resistance and was denominated Group I. The drought resistance of Group III is poor and includes the lettuce varieties 'Victoria glass crispy lettuce', 'Brera Simpson' and 'American fast-growing number 8'. The rest of the cultivars can be divided into Group II, since they exhibit a moderate degree of drought resistance.

\section{Acknowledgment}

This research was financially supported by the National Key Research and Development Program of China (2016YFD0201010) and the earmarked fund for Beijing Leafy Vegetables Innovation Team of Modern Agro-industry Technology Research System (blvt-02).

\section{References}

[1] Pan, X.Y., Wang, Y.F., Wang, G.X., Cao, Q.D. and Wang, J., 2002. The relationship between growth redundancy and size inequality in spring wheat population mulched with clear plastic film. Acta Phytoecol. Sinica, 26:177-184.

[2] Bayoumi T Y, Eid M H, Metwali E M. Application of physiological and biochemical indices as a screening technique for drought tolerance in wheat genotypes [J]. African Journal of Biotechnology, 2008, 7(14):2341-2352.

[3] Baier M, Kandlbinder A, Golldack D, et al.Oxidative stress and ozone: perception, signaling, and response [J]. Plant cell and environment, 2005, 28(8): 1012-1020

[4] Vahidi, J. 2009. Effect of water stress on germination indices in seven wheat cultivar.

[5] Gailes, J. and Ho, T.D., 1983. Multiple molecular forms of the gibberellin-induced $\infty$-amylase from the aleurone layer of barley seeds. Arch. Biochem. Biophys., 224.

[6] Pessarakli, M. 1999. Handbook of plant and crop stress. 2nd Ed., New York: Marcel Dekker Inc., 247-259.

[7] Mou, B., 2008. Lettuce. In: Prohens, J., Nunez, F. (Eds.), Handbook of Plant Breeding, Vol. I: Vegetables I: Asteraceae, -Brassicaceae, Chenopodicaceae, and Cucurbitaceae. Springer, New York, NY, USA (pp. 75-116).

[8] USDA, 2015. National Nutrient Database for Standard Reference Release 28. USDA, Washington, D.C.

[9] Baslam, M., Garmendia, I., Goicoechea, N., 2011. Arbuscular mycorrhizal fungi (AMF) improved growth and nutritional quality of greenhouse-grown lettuce. J. Agric. Food Chem. 59 (10), 5504-5515. 
[10] Hung, H.C., Joshipura, K.J., Jiang, R., Hu, F.B., Hunter, D., Smith-Warner, S.A., Colditz, G.A., Rosner, B., Spiegelman, D., Willett, W.C., 2004. Fruit and vegetable intake and risk of major chronic disease. J. Natl. Cancer Inst. 96 (21), 1577-1584.

[11] Morris, M.C., Evans, D.A., Tangney, C.C., Bienias, J.L., Wilson, R.S., 2006. Associations of vegetable and fruit consumption with age-related cognitive change. Neurology 67 (8), 1370-1376.

[12] Pavia, M., Pileggi, C., Nobile, C.G.A., Angelillo, I.F., 2006. Association between fruit and vegetable consumption and oral cancer: a meta-analysis of observational studies. Am. J. Clin. Nutr. 83 (5), 1126-1134.

[13] Kris-Etherton, P.M., Hecker, K.D., Bonanome, A., Coval, S.M., Binkoski, A.E., Hilpert, K. F., Griel, A.E., Etherton, T.D., 2002. Bioactive compounds in foods: their role in the prevention of cardiovascular disease and cancer. Am. J. Med. 113 (Suppl. 9B), 71S-88S.

[14] Soetan, K.O., Olaiya, C.O., Oyewole, O.E., 2010. The importance of mineral elements for humans, domestic animals, and plants: a review. Afr. J. Food Sci. 45 (5), $200-222$.

[15] Rauf, M., Munir, M., UI-Hassan, M., Ahmed, M. and Afzal, M., 2007. Performance of wheat genotypes under osmotic stress at germination and early seedling growth stage. African J. of Biotechnology, 8:971-975.

[16] Dhanda, S.S., Sethi, G.S., and Behl, R.K., 2004. Indices of drought tolerance in wheat genotypes at early stages of plant growth. J. Agron. Crop. Sci., 190:6-12.

[17] Heikal, M.M., Shaddad, M.A. and Ahmed, A.M., 1981. Effect of water stress and gibberellic acid on germination of flax, sesame and onion seed. Biological Plantarum, 24 (2): 124-129.

[18] Ashraf, M., Bokhari, H. Cristiti, S.N., 1992. Variation in the osmotic adjustment of lentil (Lens climates Medic) in response to drought. Acta Bot. Neerlandica. , 41:51-62.

[19] Almansouri, M., Kinet, J.M. and Lutts, S., 2001. Effect of salt and osmotic stresses on germination in durum wheat (Triticum aestivum L.). Plant Soil., 231:243-254.

[20] Okcu, G., Kaya, M.D. and Atak, M., 2005. Effect of salt and drought stresses on germination and seedling growth of pea (Pisum sativum L.).Turk J. Agric. For., 29:237-242.

[21] Kaya, M.D., Okcu, G., Atak, M., Cikili, Y. and Kolsarici, O., 2006. Seed treatments to overcome salt and drought stress during germination in sunflower (Helianthus Annuus L.). Eur. J. Agron., 24:291-295.

[22] Iqbal, M, and Ashraf, M., 2007. Seed treatment with auxins modulates growth and ion partitioning in salt-stressed wheat plants. J. Integr. Plant Biol., 49:1003-1015.

[23] ISTA., 1993. Hand book for seedling evaluation. International Seed Testing Association, Zurich, Switzerland.

[24] ISTA., 1999. International rules for seed testing. International Seed Testing Association (ISTA), Seed Science and Technology, 287, supplement.

[25] Yu Sung; Daniel J. Cantliffe; Russell T. Nagata; Warley M. Nascimento.Structural Changes in Lettuce Seed During Germination at High Temperature Altered by 
Genotype, Seed Maturation Temperature, and Seed Priming[J].JASHS.2008, Vol.133(No.2): 300-311.

[26] Kaur-Sawhney R, Tiburcio A, Altabella T, Galston A. Polyamines in plants; an overview. American journal of respiratory cell and molecular biology, 2003, 2(1):1-12 